\title{
Spectral Evidence of Early-Stage Spruce Beetle Infestation in
}

Engelmann Spruce

3 Authors: Adrianna C. Foster ${ }^{\mathrm{a}}$, Jonathan A. Walter ${ }^{\mathrm{b}}$, Herman H. Shugart ${ }^{\mathrm{c}}$, Jason Sibold ${ }^{\mathrm{d}}$, and

4 Jose Negron $^{\mathrm{e}}$

5 a. Corresponding author: University of Virginia, 296 Clark Hall, 291 McCormick Rd.

$6 \quad$ Charlottesville, VA 22904, United States

$7 \quad$ Phone: 804-380-2291

$8 \quad$ Email: acf7m@virginia.edu

9 b. Virginia Commonwealth University, 1000 W. Cary Street, Richmond, VA 23284, United

10 States; University of Kansas, 2101 Constant Ave., Lawrence, KS 66047

$11 \quad$ Email: jwalter4@vcu.edu

12 c. University of Virginia, 376 Clark Hall, 291 McCormick Rd, Charlottesville, VA 22904,

$13 \quad$ United States

$14 \quad$ Email: hhs@ virginia.edu

15 d. Colorado State University, 1787 Campus Delivery, CSU, Fort Collins, CO 80526, United

$16 \quad$ States

17 Email: Jason.Sibold@ colostate.edu

18 e. USDA Forest Service, Rocky Mountain Research Station, 240 West Prospect, Fort

19 Collins, CO 80526, United States

20 Email: jnegron@fs.fed.us

21 


\section{Abstract}

23 Spruce beetle (Dendroctonus rufipennis (Kirby)) outbreaks cause widespread mortality of

24 Engelmann spruce (Picea engelmannii (Parry ex Engelm)) within the subalpine forests of the

25 western United States. Early detection of infestations could allow forest managers to mitigate

26 outbreaks or anticipate a response to tree mortality and the potential effects on ecosystem

27 services of interest. However, the subtle changes in the foliage of infested spruce make early

28 detection difficult. An experiment was conducted in southern Colorado to determine important

29 wavelengths for detecting early-stage (i.e. recently infested) spruce beetle infestation in

30 Engelmann spruce. Spectral reflectance from non-infested and recently infested spruce needles

31 were obtained using the ASDi Field-Spec Pro spectroradiometer. After pre-processing, random

32 forest analysis was used to identify hyperspectral bands and aggregations of hyperspectral bands

33 corresponding to Landsat TM bands and vegetation indices that effectively discriminated

34 between non-infested and infested trees. Results show that the shortwave infrared region of the

35 electromagnetic spectrum was a key area for detecting early stages of spruce beetle infestation,

36 likely due to the effects of beetle infestation on water transport within Engelmann spruce. The

37 strong discriminability of bands in the shortwave infrared region indicates a potential for this

38 spectral region to be used to detect early-stage spruce beetle infestation over larger areas using

39 multispectral satellite imagery. In a preliminary trial, we found that a time series of reflectance in

40 Landsat TM band 7 (shortwave infrared) was strongly correlated with the progression through

41 time of a spruce beetle outbreak in southern Wyoming. These findings suggest that multispectral

42 indicators of early-stage spruce beetle outbreak can be developed. These indicators are needed to

43 better understand spatiotemporal dynamics of spruce beetle outbreaks, and can be used by forest 
44 managers to detect early stages of spruce beetle infestation and to potentially mitigate some 45 spruce mortality.

\section{Keywords}

47 bark beetle; hyperspectral; insect infestation; Landsat; shortwave infrared; vegetation stress 48 


\section{Introduction}

The spruce beetle (Dendroctonus rufipennis (Kirby)) is an important mortality agent of

52 spruce species (Picea spp.) throughout the western United States and Canada (Bentz et al.,

53 2010). Within the subalpine forests of the southern Rocky Mountains, its primary host is

54 Engelmann spruce (Picea engelmannii (Parry ex Engelm)) (Bebi et al., 2003; Schmid and Frye,

55 1972). Historically, spruce beetle infestations, along with fire, have been the most important

56 natural disturbances shaping forest structure and function in subalpine forests, and both of these

57 agents are anticipated to increase under a warming climate (Bentz et al., 2010; DeRose and

58 Long, 2012; Hart et al., 2014; Veblen et al., 1991; Westerling et al., 2006). Bark beetle outbreaks

59 have caused widespread tree mortality across the US and Canada in the last several decades,

60 especially in Colorado (Bentz et al., 2009; Berg et al., 2006). In a Colorado outbreak lasting from

611939 to 1952, spruce beetles affected over 290,000 ha of the landscape (Anderson et al., 2010;

62 Veblen et al., 1991), and an ongoing outbreak in Colorado has affected over 638,000 ha between

631996 and 2015 (USFS, 2016). These landscape-scale mortality events modify the size structure

64 and species composition of forests, especially in terms of basal area, average tree height, and

65 stem density (Derderian et al., 2016; Hawkins et al., 2012; Humphreys and Safranyik, 1993).

66 Biogeochemical cycling in forests is also affected by bark beetle outbreaks, through reduction in

67 stomatal conductance and canopy transpiration (Edburg et al., 2012; Frank et al., 2014),

68 increases in leaf litter and coarse woody debris (Edburg et al., 2012; Meddens et al., 2012), and

69 changes in the carbon balance of the forest (Brown et al., 2012; Edburg et al., 2012; Kurz et al.,

70 2008).

71 Detection and monitoring of bark beetle outbreaks is crucial to forest management and to

72 deciphering the ecological effects of these organisms. The effects of beetle infestations may be 
73 mitigated through various management techniques such as clearing of wind thrown trees,

74 selective thinning, pheromone trapping, and burning (Hansen et al., 2010; Humphreys and

75 Safranyik, 1993; Kautz et al., 2011), especially if these infestations are detected early on in the

76 outbreak cycle (DeRose and Long, 2012; Jenkins et al., 2014). Perhaps more importantly, the

77 relative success of forest treatments as well as the mechanisms and environmental characteristics

78 that lead to outbreaks can be investigated through detection and monitoring of infestation stage

79 and extent (Walter and Platt, 2013).

80 Aerial detection surveys are often used to assess mortality trends caused by bark beetles

81 (USFS, 2016). Bark beetle-killed trees change in coloration as they desiccate, from green to

82 yellow-green, and with some species to a bright red, and this color change is used as an indicator

83 to map tree mortality. However, this visual detection is not possible in the early (i.e. green)

84 stages of infestation, potentially too late to be helpful for effective management techniques

85 (Franklin et al., 2003). In the case of the closely related mountain pine beetle (Dendroctonus

86 ponderosae (Hopkins)), which in the Rocky Mountains infests several Pinus species, the foliage

87 of infested trees changes to bright red within one year of being attacked (White et al., 2007). The

88 foliage of spruce beetle-infested Engelmann spruce, however, remains green to yellow-green and

89 photosynthesizing (albeit only slightly) for two or more years after the initial infestation (DeRose

90 et al., 2011; Frank et al., 2014; Schmid, 1976). This several year window of green-stage spruce

91 beetle attack when beetle populations are growing, but detection is difficult, may allow for

92 spruce beetle outbreaks to reach unmanageable levels. Additionally, while aerial surveys are

93 relatively cost-effective for the amount of forest health characteristics that they can provide, and

94 are useful for portraying trends in insect and disease activity, the information is generally at a 
95 coarse spatial scale, and may have low positional accuracy (Hall et al., 2016; Wulder et al., 96 2006c).

97 In comparison to aerial surveys, remote sensing may allow for more extensive,

98 consistent, and finer-resolution mapping of bark beetle damage, as well as early detection of

99 beetle infestation. To be useful for effective and timely management planning and ecosystem

100 response studies, however, pertinent areas of the electromagnetic spectrum for detecting early-

101 stage spruce beetle infestations must be determined. Many studies have used remote sensing

102 instruments to detect red-stage, and to a lesser extent, green-stage mountain pine beetle

103 outbreaks across a broad range of its hosts, but with varying conclusions on the best waveband or

104 vegetation index to use (Coops et al., 2006a; Franklin et al., 2003; Hall et al., 2016; Meddens and

105 Hicke, 2014; Niemann et al., 2015; Skakun et al., 2003; White et al., 2007, 2005; Wulder et al.,

106 2006a, 2006b). Goodwin et al. (2008) were able to identify red-stage infestation across a large

107 study area ( 1.5 million ha) in British Columbia, Canada using Landsat imagery and the

108 normalized difference moisture index (NDMI). Coops et al. (2006a) and Hicke and Logan (2009)

109 both used high spatial resolution QuickBird imagery to accurately map red-attack mountain pine

110 beetle damage using the red-green index (RGI). In contrast, White et al. (2007) found that the

111 moisture stress index (MSI) had the strongest relationship with proportion of red-attack damage

112 using QuickBird and Hyperion imagery.

113 Much of the success in detecting and monitoring mountain pine beetle outbreaks in

114 broad-scale remote sensors can be attributed to the strong red signature associated with a

115 mountain pine beetle infestation. In contrast, the success of spruce beetle monitoring studies has

116 been more limited. Foliar changes in infested Engelmann spruce are more subtle, and Engelmann

117 spruce typically occurs in mixed spruce-fir stands, unlike generally mono-specific pine stands. 
118 The few existing studies on outbreak detection using multispectral remote sensing have been

119 restricted to large-scale outbreaks, or to detecting outbreaks two years or longer into the

120 infestation (DeRose et al., 2011; Frank et al., 2014; Hart and Veblen, 2015; Makoto et al., 2013).

121 DeRose et al. (2011) and Hart and Veblen (2015) utilized multispectral imagery to detect gray-

122 stage spruce beetle infestation with high accuracy using the disturbance index (DI), red-green

123 index (RGI), blue-red index (BR), and normalized difference vegetation index (NDVI).

124 However, spruce trees at the gray stage have already been infested for at least two years

125 (Schmid, 1976), and have started to drop their needles, a point in the outbreak cycle which may

126 be too late for a management response. This difficulty in detecting early-stage spruce beetle

127 infestations suggests a need for higher-sensitivity remote sensors to identify pertinent wavebands

128 for detecting and studying early-stage spruce beetle outbreaks.

129 Following a spruce beetle infestation, Engelmann spruce close their stomata, resulting in

130 decreased canopy conductance and canopy evapotranspiration (Frank et al., 2014). These and

131 other changes to the foliage of infested spruce may be observable in fine-scale hyperspectral data

132 (Asner et al., 2015; Fassnacht et al., 2014), promising improved algorithms for determining the

133 location and extent of a spruce beetle infestation. Biochemical processes in plants, such as

134 photosynthesis, respiration, and transpiration, are inherently linked to the concentrations of the

135 biochemicals involved in them (Curran et al., 2001). As such, changes initiated by stress,

136 drought, or other factors result in a change in the foliar chemistry of plants. These foliar

137 chemistry changes are often observable in hyperspectral sensors, which detect spectral

138 reflectance in narrow wavebands of the electromagnetic spectrum (Hall et al., 2016; Kokaly and

139 Clark, 1999). Many studies have had success using aerial and ground-based hyperspectral

140 sensors to detect differences in spectral reflectance between leaves with varying pigments, 
141 vegetation stress, and bark beetle damage (Carter, 1994; Carter and Knapp, 2001; Delalieux et

142 al., 2009; Fassnacht et al., 2014; Masaitis et al., 2013; Naidu et al., 2009; Santos et al., 2010;

143 Smith et al., 2004). Nasi et al. (2015) used a hyperspectral sensor onboard an unmanned airborne

144 vehicle to detect various stages of European spruce bark beetle (Ips typographus) infestation in

145 Norway spruce (Picea abies (L. Karst.)). Niemann et al. (2015) and Cheng et al. (2010) both

146 used high spectral resolution sensors to distinguish between healthy and green-stage mountain

147 pine beetle attack, finding the near infrared and shortwave infrared regions to be the most useful.

148 Ahern (1988) also found evidence for detection of green-stage mountain pine beetle infestation

149 using lab spectroscopy, and a study by Carter and Knapp (2001) found significant differences in

150 the 500 to $700 \mathrm{~nm}$ range between lab-derived spectra of healthy and nitrogen-stressed radiata

151 pine (Pinus radiata (D. Don)). The success of these studies at using hyperspectral sensors to

152 detect subtle foliar changes due to vegetation stress lends support to the use of hyperspectral data

153 to detect green-stage spruce beetle infestation in Engelmann spruce.

154 It is clear that hyperspectral remote sensing, with its fine spectral and often fine spatial

155 resolution, can provide detailed biophysical information on canopy properties such as moisture,

156 leaf nitrogen content, leaf pigment, and tree stress level (Asner et al., 2011; Calderón et al., 2013;

157 Carlson et al., 2007; Kokaly et al., 2009; Underwood et al., 2003). These properties make

158 hyperspectral sensors ideal tools for detecting subtle foliar changes in response to disturbances

159 such as bark beetle infestations. However, the use of aerial and ground-based hyperspectral

160 instruments is expensive and time-consuming, especially when considering large forest

161 landscapes. Multispectral imagery is much more readily available and has a large enough

162 spatiotemporal coverage to monitor yearly or sub-yearly changes in large areas. Thus, freely

163 available broadband imagery is best suited for monitoring whole forest landscapes over time, 
164 producing actionable data that forest managers can use to mitigate and predict the spread of

165 insect outbreaks. Yet the low spectral resolution of broadband sensors hinders the process of

166 discovering wavelengths and wavebands important to detecting infestations. These issues present

167 a need for information about such pertinent wavebands to be garnered in local-scale,

168 hyperspectral studies such that they may be scaled up for use in broad-scale monitoring

169 campaigns.

170 In this study, we use ground-based hyperspectral measurements from the needles of

171 recently infested and non-infested Engelmann spruce to determine areas of the electromagnetic

172 spectrum that could be used to detect early stages of spruce beetle infestation. We use the

173 information garnered from this high spectral and spatial resolution experiment to develop a case

174 for detection of early-stage spruce beetle outbreaks in broad-scale remote sensors (i.e. Landsat, 175 Hyperion, EO-1).

176 2. Methods

177 2.1. Study area

178 This study was conducted at Monarch Pass, a high-elevation site within the spruce-fir

179 (Picea engelmannii and Abies lasiocarpa) zone of the southern Rocky Mountains (Fig. 1).

180 Monarch Pass ( $38^{\circ} 30^{\prime} 10.08^{\prime \prime} \mathrm{N}, 106^{\circ} 20^{\prime} 8.1594 " ; 3442 \mathrm{~m}$ ) is located in the Sawatch Range of

181 the Rocky Mountains, Grand Mesa-Uncompahgre-Gunnison National Forests, near Salida, CO.

182 This site contains Engelmann spruce trees in various stages of infestation (non-infested, recently

183 infested, and beetle-killed trees). Annual precipitation in the area is $60 \mathrm{~cm}$, and mean monthly

184 temperatures are $14^{\circ} \mathrm{C}$ and $-5^{\circ} \mathrm{C}$ for July and January, respectively (NCDC, 2016).

185 2.2. Hyperspectral data collection 
187 spectroradiometer capable of measuring spectral response over 366 bands, covering wavelengths

188 from 350 to $2500 \mathrm{~nm}$. The spectral resolution of the FieldSpec Pro is $3 \mathrm{~nm}$ for wavelengths

189 between 350 and $1000 \mathrm{~nm}$ and $10 \mathrm{~nm}$ for wavelengths between 1000 and $2500 \mathrm{~nm}$. In order to

190 collect this full wavelength range, the FieldSpec Pro contains three separate spectroradiometers:

191 VNIR (visible and infrared), and SWIR-1 and SWIR-2 (shortwave infrared). Data from this

192 instrument can thus provide information on the spectral properties of leaves in the visible, near

193 infrared, and shortwave infrared regions of the electromagnetic spectrum.

194 Engelmann spruce trees were first identified as non-infested or recently infested. Spruce

195 beetles infest their hosts by boring into the bark and laying eggs in the phloem of infested trees

196 (DeRose and Long, 2012). Eggs hatch after a few days and the larvae feed on the tree's phloem.

197 Newly infested trees were identified by the presence of boring dust at bark crevices and the base

198 of the tree, pitch tubes or resin exudation from the bole, and newly constructed egg galleries in

199 the phloem. The flight period when new trees are attacked by spruce beetles reaches its highest

200 point towards the end of July (Negron, unpublished data). As our sampling took place in early

201 September, measurements collected from infested trees took place about 8 weeks after

202 infestation.

203 Field spectra were collected from 30 spruce trees (15 non-infested, and 15 recently

204 infested) during early September 2014 using the point of contact (POC) method. In this method,

205 the POC probe is placed in direct contact with the sample using a foliage clip, such that no light

206 escapes the POC and no external light is able to affect the sampling. This method uses an internal

207 light source (a quartz-halogen lamp), so sun angle and cloudiness do not affect sampling. Three

208 spectral subsamples were taken from the needles of two branches per tree: one at about $2 \mathrm{~m}$, and 
209 a second branch at about $6 \mathrm{~m}$ in height (i.e. a total of 90 subsamples for each infestation type).

210 Two branches from each tree were tested to determine if height on the tree had any effect on the

211 spectral signal for spruce beetle infestation. Coloration changes in infested Engelmann spruce

212 trees occur first in the branches of the upper crown (Schmid and Frye, 1977). Because we

213 collected reflectances from branches in the lower canopy, spectral differences between infested

214 and non-infested Engelmann spruce found in this study may be somewhat conservative.

215 The branches used were clipped from the spruce trees and immediately sampled so as to

216 reduce error associated with being detached from the tree for an extended time period. Each of

217 the three samples per branch was measured using different needles on the branch, and care was

218 taken to only collect spectral signatures from green needles. Each sample involved measuring

219 reflectance of several spruce needles at once. The needles of each sample were arranged on the

220 POC clip so as to maximize the amount of reflected surface area, but minimize overlap and

221 shadowing of needles. Instrument optimization and white reference calibration were conducted

222 after each branch was sampled to correct for atmospheric, temperature, and other changes that

223 may have affected sampling.

\section{2.3. Hyperspectral data processing}

225 First, splice corrections were conducted on all reflectance spectra subsamples. This

226 process reduces discontinuities arising from the three separate detectors (VNIR, SWIR-1, SWIR-

227 2) used to collect the full 350 to $2500 \mathrm{~nm}$ wavelength range. The three subsamples per branch

228 were then averaged. These initial processing methods were all conducted using ViewSpec Pro

229 Software (Analytical Spectral Devices, Inc; Boulder, CO).

230 Continuum removal was then performed on the 30 branch spectra using ENVI version 5.2

231 (Exelis Visual Information Solutions; Boulder, CO). Continuum removal reduces spectral 
232 changes due to non-foliar influences such as instrument drift (Kokaly and Clark, 1999). First, a

233 convex hull (or continuum) is fitted over the top of each spectrum that connects local spectral

234 maximums. The continuum-removed reflectance is then calculated by dividing the reflectance

235 values in the original spectrum by the reflectance values of the continuum. This allows for

236 absorption pits to be enhanced and noise due to instrument or other errors to be reduced

237 (Underwood et al., 2003). Finally, it was determined that branch height had no statistical effect

238 on the spectral signals of infested and non-infested trees (see Fig. S1 in the Supplementary

239 Material; $\mathrm{p}>0.05$ ), so the spectral signatures of high and low branches were averaged for each

240 tree.

241 2.4. Hyperspectral statistical analyses

242 In order to determine important wavelengths for differentiating between infested and

243 non-infested trees, a random forest (Breiman, 2001) regression was implemented in R (R Core

244 Team 2014) using the package 'randomForest' (Liaw and Wiener, 2002). Measures of variable

245 importance are an increasingly popular method for variable reduction and for determining which

246 variables best predict the response variable in question (Breiman, 2001; Strobl et al., 2007). In

247 the case of analyzing hyperspectral data, thousands of variables (i.e. reflectance in different

248 wavebands) are collected, and it is imperative that redundant bands are removed and the most

249 important variables for the study at hand are determined (Thenkabail et al., 2012a). The random

250 forest algorithm creates multiple, uncorrelated decision trees using different random subsets of

251 the data and different predictor variables (i.e. different wavelengths). The use of multiple

252 decision trees increases the classification accuracy of the algorithm. Variable importance is then

253 based on the number of times each variable is chosen by different individual decision trees in the 
254 random forest and how much each variable contributes to the overall accuracy of the model

255 (Strobl et al., 2007).

256 Next, the most important wavelengths determined by the random forest were chosen and

257 receiver operator characteristic (ROC) curves were generated on predictions of infested vs. non-

258 infested from classification trees using each of the important variables individually. ROC curves,

259 which plot the rate of true positives against the rate of false positives, can be used to visualize a

260 predictor variable's ability to correctly predict the response variable (i.e. infested or non-

261 infested). The area under the curve (AUC) of an ROC curve represents the probability of the

262 predictor variable accurately choosing the positive case when given a positive and negative test

263 case, and is a widely used test of classification algorithms (Eng, 2005). An AUC of 0.50 is

264 equivalent to random chance. We also generated a confusion matrix (a table for visualization of

265 model performance; Fawcett, 2006) for each wavelength, and from each matrix calculated the

266 overall accuracy, false positive rate, and false negative rate of each wavelength. Next, $t$-tests

267 were conducted to determine if differences between non-infested and infested spruce in spectral

268 reflectance over the eight selected wavelengths were statistically significant. ROC curves,

269 confusion matrices, and $t$-tests were also conducted for several vegetation indices commonly

270 used for vegetation studies and for averages of wavelengths representing Landsat wavebands

271 (Table 1). This was done to determine if an index or a particular waveband in Landsat could also

272 identify early spruce beetle infestation in Engelmann spruce. We chose vegetation indices

273 commonly used to detect bark beetle infestations (Coops et al., 2006a; DeRose et al., 2011;

274 Meddens et al., 2011) as well as those used to detect vegetation stress in general (Calderón et al.,

275 2013; Naidu et al., 2009; Roberts et al., 2012).

276 3. Results 
278 infested Engelmann spruce overlap (Fig. 2). However, there is divergence in the absorption pit

279 around $1440 \mathrm{~nm}$ and across the shortwave infrared region between 1900 and $2480 \mathrm{~nm}$. The

280 spectral reflectance from infested spruce is higher in these regions than that of the non-infested

281 spruce, though this difference is somewhat small (Fig. 3). The random forest regression found

282 several important wavelengths for determining infestation in the Engelmann spruce spectra; most

283 of these are in the far near infrared to shortwave infrared regions (Table 2). We chose the top

284 eight wavelengths to generate classification trees and ROC curves because wavelengths chosen

285 by the random forest algorithm after these eight contributed minimally to overall accuracy. Many

286 of these important wavelengths had high AUC and accuracy values, and low overall error rates

287 (Table 2).

$288 \quad$ Vegetation indices and averaged Landsat bands derived from the field spectra had lower

289 AUCs and accuracies than did individual hyperspectral bands (Table 2; see Table S1 in the

290 Supplementary Material for contingency matrices). Of these, the red-green index (RGI), water

291 index (WI), NDVI, and Landsat band 7 yielded the highest accuracies. We chose to conduct $t$ -

292 tests comparing the reflectance of infested/non-infested samples on the top eight important

293 wavelengths and vegetation indices/Landsat bands with accuracy values above 0.80 . The results

294 of these $t$-tests are consistent with the results of the classification trees (Table 3).

\section{4. Discussion}

296 Early detection of spruce beetle outbreaks may allow forest managers to mitigate an

297 infestation before it turns into a devastating outbreak. A study by DeRose and Long (2012) found

298 evidence for multiple nascent spruce beetle infestations across the study landscape, which the

299 authors posited could only be slowed during the early stages of the outbreak. Once an infestation 
300 is identified, managers can potentially reduce the growth rate of spruce beetle populations and

301 limit the severity and extent of growing outbreaks through removal of individual infested trees or

302 downed logs (Hansen et al., 2010). These mitigation techniques would be best applied in areas

303 with high recreational or ecological value and should be applied before infestations reach

304 outbreak levels, during the early, or green stages of beetle infestation. By the time spruce beetle-

305 attacked trees have reached the gray stage, the insects have long since abandoned the tree and

306 initiated new infestations, contributing to the growing outbreak (Schmid and Frye, 1977).

307 Detecting and removing early-stage attacked trees may prevent some of the beetles still within

308 the trees from infesting others, possibly mitigating some mortality. Thus, in order to successfully

309 monitor, manage, and study these important disturbance agents, forest managers and researchers

310 would benefit from an early-stage indicator of spruce beetle infestation. Such an indicator would

311 be made even more useful if it could be applied in sensors with broad spatial coverage and

312 whose data are readily available, such as that of the Landsat series. Until now, remote sensing

313 studies have been focused on detecting gray-stage or later spruce beetle infestations (DeRose et

314 al., 2011; Frank et al., 2014; Hart and Veblen, 2015). This study has the capacity to bridge this

315 knowledge gap and provide insight into what wavebands and indices should be used to detect

316 early-stage spruce beetle infestation.

317 In this study, we identified several wavelengths and vegetation indices that have potential

318 as indicators of early-stage spruce beetle infestation at the branch and needle level. Of these,

319 several wavelengths in the shortwave infrared region may be most useful (Table 2; Fig. 2).

320 Though reflectances at 368 (ultraviolet) and 764, 861, and 862 (NIR) nm differed between non-

321 infested and infested vegetation and had high overall accuracy values (Tables 2; 3), the mean

322 differences between infested and non-infested reflectances at these wavelengths, while 
323 significant, were quite small. These small differences, manifested in such narrow, specific

324 wavelengths, may be difficult to detect in coarser resolution sensors such as Landsat or

325 QuickBird. These results point to the SWIR region as a better indicator of spruce beetle

326 infestation, especially as the area of divergence between non-infested and infested spruce in this

327 region overlaps well with multispectral SWIR bands such as Landsat band 7 (Fig. 2).

328 Overall, the individual chosen hyperspectral wavelengths were better predictors of early-

329 stage spruce beetle infestation than were the vegetation indices/Landsat bands (Table 2).

330 Although we focus on a different stage of infestation, our findings are similar to those of Hart

331 and Veblen (2015), who also found differences between RGI and NDVI for healthy and infested

332 trees. Also in agreement with Hart and Veblen (2015) and DeRose et al. (2011), the disturbance

333 index had a good AUC, at 0.77 . However, DI was not the best metric in our case, possibly

334 because we detected green-stage infestation, rather than gray-stage or later. Landsat band 7 also

335 had the lowest error rates of all the calculated indices (Table 2). While commission errors (i.e.

336 false positives) should be avoided, choosing an indicator with a moderate false positive rate, but

337 a low false negative rate would avoid missing infestations altogether.

338 The higher reflectance of infested spruce in the shortwave infrared region (Fig. 2) can be

339 explained by the underlying physiology of a spruce beetle attack. When a spruce tree is

340 successfully infested by spruce beetles, it receives damage in the form of cambium and phloem

341 consumption by spruce beetle larvae as well as infection with blue-stain fungus, which is

342 vectored by the spruce beetle (Paine et al., 1997; Schmid and Frye, 1977). Frank et al. (2014)

343 found that while canopy conductance of infested Engelmann spruce trees is significantly lower

344 than that of healthy spruce, there is no difference in photosynthesis between rehydrated branches

345 of either class. This suggests that infested spruce trees are tightly regulating their stomatal 
346 conductance in response to the hydraulic impacts of the blue stain fungus, while maintaining leaf

347 biochemistry (Frank et al. 2014). Thus, in the early stages of a spruce beetle infestation,

348 Engelmann spruce are slowly losing water due to the decreased canopy conductance, which

349 results in an increase in reflectance in the shortwave infrared region, a primary area for radiation

350 absorption by water (Thenkabail et al., 2012b; Ustin et al., 2004).

351 A natural extension of these findings would be to evaluate the feasibility of using the

352 wavebands and spectral indices identified in this fine-scale, hyperspectral study as indicators of

353 stand-level early-stage spruce beetle outbreaks in broad-scale imagery, thus providing a more

354 useful and accessible monitoring tool for forest managers. However, several factors complicate

355 extrapolation of these findings. Scaling up from field spectra to broad-scale multispectral

356 imagery such as that of Landsat is complicated by the differences in spectral, spatial, and

357 radiometric resolutions, as well as the differences in the amount of non-foliar reflectance

358 captured in either type of sensor (Coops et al., 2006a; Hall et al., 2016; Lillesand et al., 2000). Of

359 these, non-foliar influences and radiometric resolution are likely to be the least limiting. Non-

360 foliar influences present in broadband pixels can be amended through adequate image selection,

361 classification into vegetated vs. non-vegetated surfaces, and by a number of atmospheric and

362 topographic corrective techniques (Bhandari et al., 2012; Hall et al., 2016; Riano et al., 2003).

363 Additionally, we found fairly strong differences broadly across the SWIR region (Fig. 2); thus

364 radiometric resolution differences between the FieldSpec Pro and broadband satellites are also

365 not likely to be problematic, especially given the high radiometric resolution of newer satellites

366 (e.g. with the 16-bit Landsat OLI).

367 Decreasing spectral resolution is a large hindrance associated with scaling from

368 hyperspectral to broad-scale sensors (Coops et al., 2006b). Nonetheless, we found evidence for 
369 increased reflectance in infested spruce foliage across a broad range of the shortwave infrared

370 region ( 1900 to $2400 \mathrm{~nm}$; Fig. 2, 3), indicating that multispectral bands in this region (i.e.

371 Landsat band 7) may be useful for detection of early spruce beetle infestation in broadband

372 imagery. The high accuracy and relatively low error rates associated with the averaged Landsat

373 band 7 from the field spectra (Tables 2; 3) also support its utility in detecting early infestations.

374 We additionally found high accuracy with NDVI and RGI (Table 2), which can also be

375 calculated using broad wavebands (Table 1).

376 Spatial resolution is also important to consider when conducting vegetation change

377 studies with remote sensing (Coops et al., 2006b; Hall et al., 2016). Sensors with high spatial

378 resolution can detect changes at the scale of single trees or branches, as with the ASDi FieldSpec

379 Pro. However, high spatial resolution typically comes at the expense of low spatial extent and

380 high cost (monetary and time/effort) per unit of information (Coops et al., 2006b; Hall et al.,

381 2016). In our case, the FieldSpec Pro can only sample one branch at a time, and it is not feasible

382 to sample a whole landscape this way. More moderate spatial resolution sensors such as Landsat

383 and Hyperion (each with $30 \mathrm{~m}$ pixels) can detect changes at the level of a forest stand (Coops et

384 al., 2006b; Goodwin et al., 2008; Walter and Platt, 2013), cover large areas, and have return

385 times on the order of several days, thereby allowing for identification of stressed stands

386 undergoing early signs of beetle infestation as well as monitoring of infestations through time.

387 To assess whether the wavelengths identified in our hyperspectral analysis could be used

388 to discriminate spruce beetle infestation in broad-scale multispectral imagery, we conducted a

389 preliminary assessment of Landsat imagery of a recent spruce beetle outbreak in southern

390 Wyoming. The USFS/AmeriFlux site Glacier Lakes Ecosystem Experiments Site (GLEES; in the

391 subalpine zone of the southeastern WY Rocky Mountains) underwent an extensive spruce beetle 
392 outbreak between 2005 and 2010 (Frank et al., 2014). Frank et al. (2014) investigated whether

393 they could detect the early stages of this infestation using the MODIS green leaf area product,

394 however, evidence for the outbreak was not observable in MODIS data until about two years

395 after the peak of the outbreak had already occurred. MODIS has a fairly low spatial resolution

396 (250-1000 m) compared to the Landsat series (30 m). Through the use of a finer spatial

397 resolution satellite, and the wavebands identified in our hyperspectral analysis, it is possible that

398 the 2005 spruce beetle outbreak at GLEES may be detectable in Landsat imagery, even in the

399 early stages of the outbreak. If wavelengths identified in our hyperspectral analysis are in fact

400 able to detect infestation at coarser spatial scales and spectral resolutions, this should manifest as

401 coherent changes in corresponding Landsat bands.

402 We conducted a preliminary case test to begin evaluating the potential for early-stage

403 infestation identification in multispectral satellite imagery. We focused on Landsat band 7 (2080-

$4042350 \mathrm{~nm}$ ), RGI, and NDVI because of the substantial differences between the foliage of non-

405 infested and infested trees found over these bands and indices in the hyperspectral data. Late

406 summer Landsat 5 TM imagery was used to calculate average rescaled digital number (DN)

407 values for RGI, NDVI, and band 7 for the GLEES outbreak, and these values were plotted across

408 the infestation time series along with data on cumulative percent spruce attacked from Frank et

409 al. (2014) (see Appendix A for more detailed methodology). There was an overall increase in

410 reflectance from Landsat band 7 between 2003 and 2011, coherent with the increase in

411 cumulative attacked spruce with 2010 (Fig. 4). The red-green index had an early peak in 2006

412 and then seemed to follow reflectance from Landsat band 7, whereas NDVI peaked in 2007 and

413 then decreased. Pearson's correlation coefficients between the attack data and Landsat band 7,

414 RGI, and NDVI are 0.854, 0.690, and -0.485, respectively (see Appendix A for further results). 
The coherent changes in the Landsat data record and percent spruce attacked lend support

416 to the idea that stand-level spruce beetle infestation can be detected in broadband imagery, with

417 the potential for detection of green-stage outbreaks. Both Landsat band 7, and to some extent

418 RGI, correlated well with the progression of spruce beetle-attacked trees at GLEES (Fig. 4).

419 Band 7 and RGI also increased prior to when this attack could be identified in MODIS data

420 (Frank et al. 2014), and prior to a visual change in the canopy (see photos taken during the

421 infestation in Fig. S2 in Supplementary Material). These increases in RGI and band 7 in the

422 Landsat record prior to visible changes to the canopy further support their utility as green-stage

423 indicators of spruce beetle infestation. Future studies investigating the use of Landsat band 7 and

424 RGI to detect early-stage spruce beetle infestations should include spatially detailed ground

425 truthing at multiple locations and in different times, including all classes of infestation stage.

426 However, the fact that we did see a change in the averaged wavebands and indices, even with the

427 added influence of other infestation classes and other non-foliar influences, lends further support

428 to their use as green-stage indicators of spruce beetle infestation in broadband imagery. Our

429 intent with this preliminary assessment is to bolster the argument for use of information gained at

430 the fine-scale to be used in the more readily available and comprehensive broad-scale satellite

431 record.

432 The large differences between infested and non-infested spruce in the SWIR region (Fig.

433 2), relatively high accuracy values of Landsat band 7 and RGI in the hyperspectral data (Table

434 2), and the early increases in band 7 and RGI in the Landsat imagery at GLEES (Supplemental

435 Figure S2) implicate the shortwave infrared region and the red-green index as good candidates

436 for detecting early stages of spruce beetle infestation, potentially in broad-scale imagery. This

437 tool would provide managers and other researchers with an easier, more cost-effective way of 
438 identifying and potentially mitigating areas of spruce beetle infestation. Many studies have used

439 RGI and the SWIR region to detect vegetation stress due to infestations (Apan et al., 2004;

440 Cheng et al., 2010; Coops et al., 2006a; Delalieux et al., 2007; Hart and Veblen, 2015; Hicke and

441 Logan, 2009; White et al., 2007). Complications with using the SWIR region to detect moisture

442 stress due to early-stage spruce beetle infestations arise from the possibility of misclassifying

443 drought-related stress as a spruce-beetle infestation, or vice versa. Controlling for soil moisture

444 or precipitation using weather or flux tower data could alleviate this problem. However, spruce

445 forests undergoing drought stress are also more likely to be infested by spruce beetles (Berg et

446 al., 2006; Hart et al., 2014; Hebertson and Jenkins, 2008; Malmstrom and Raffa, 2000;

447 McKenzie et al., 2009; Sherriff et al., 2011), and as such detecting spruce forests undergoing

448 drought-related stress may help to identify areas predisposed to infestation.

449 These findings are an important step towards developing an early-stage detection and

450 monitoring tool for spruce beetle outbreaks, and can serve as the foundation for further studies.

451 Successful monitoring and management of growing spruce beetle outbreaks may help dampen

452 tree mortality and curtail the expansion of infestations. Such monitoring, especially when applied

453 at the early stages of outbreaks, may also provide insight into what climate and environmental

454 factors prompt outbreaks, and what factors influence their spread. Such techniques can be

455 applied locally within the Colorado Rocky Mountains, more broadly across the entire spruce

456 beetle's range, as well as across the ranges of other similar bark beetle species.

\section{5. Conclusions}

458 Under outbreak conditions, spruce beetles can be devastating to the landscape, with

459 consequences ranging from widespread mortality of Engelmann spruce to loss of slope stability

460 and changes in the carbon, water, and energy balances of the forest (Dale et al., 2001; Edburg et 
461 al., 2012; Kurz et al., 2008; Veblen et al., 1991). Early detection of spruce beetle infestations

462 would aid in the study of their outbreak dynamics and may help mitigate large-scale outbreaks.

463 Ground-based hyperspectral remote sensing, with its fine spatial and spectral resolution, has been

464 proven to be a valuable tool for understanding the subtle changes in vegetation due to various

465 types of stress and for determining pertinent wavelengths, spectral regions, and vegetation

466 indices useful for classifying healthy and stressed vegetation (Ahern, 1988; Carter, 1993;

467 Delalieux et al., 2007; Santos et al., 2010). The information garnered with such small-scale data

468 can be used to inform studies involving more readily available broadband imagery. We have

469 found, through the use of a ground-based spectroradiometer, that the shortwave infrared region

470 and the red-green index may be useful identifiers of green-stage spruce beetle infestation in

471 Engelmann spruce. Although we had higher accuracy values for the specific wavelengths of the

472 spectroradiometer than those for the aggregated wavebands or vegetation indices, our findings

473 suggest that these wavebands and indices may also be useful for detecting stand-wide outbreaks

474 using broad-scale multispectral sensors such as Landsat. Our results can be used to inform other

475 studies on detecting and following spruce beetle outbreaks, and perhaps for studies on detecting

476 early-stage infestations from other bark beetles within the Rocky Mountains landscape.

\section{6. Acknowledgements}

478 This work was funded by the VA Space Grant Consortium Graduate Fellowship (VSGC

479 FY 15-16 to A.C.F., project title "Understanding spruce beetle outbreak dynamics and their

480 response to climate change through remote sensing and ecological modeling”) and by a grant

481 from the National Fish and Wildlife Foundation (grant number: 0106.12.032847) to A.C.F.

482 J.A.W. was supported in part by USDA-NIFA 2016-67012-24694. We also thank Sunnie Long

483 for her technical advice and expertise with using the FieldSpec Pro, John Frank and Heather 
484 Speckman for use of canopy photography from GLEES, as well as three anonymous reviewers 485 for their very useful comments during the editing and revising of this manuscript. 


\section{References}

488 Ahern, F., 1988. Effects of bark beetle stress on the foliar spectral reflectance of lodgepole pine. Int. J. Remote Sens. 9, 1451-1468.

Anderson, R.S., Smith, S.J., Lynch, A.M., Geils, B.W., 2010. The pollen record of a 20th century spruce beetle (Dendroctonus rufipennis) outbreak in a Colorado subalpine forest, USA. For. Ecol. Manag. 260, 448-455. doi:10.1016/j.foreco.2010.05.001

Apan, A., Held, A., Phinn, S., Markley, J., 2004. Detecting sugarcane "orange rust" disease using EO-1 Hyperion hyperspectral imagery. Int. J. Remote Sens. 25. doi:10.1080/01431160310001618031

Asner, G., Martin, E.M., Kapp, D.E., Tupayachi, R., Anderson, C., Carranza, L., Martinez, P., Houcheime, M., Sinca, F., Weiss, P., 2011. Spectroscopy of canopy chemicals in humid tropical forests. Remote Sens. Environ. 115, 3587-3598.

Asner, G.P., Martin, R.E., Anderson, C.B., Knapp, D.E., 2015. Quantifying forest canopy traits: imaging spectroscopy versus field survey. Remote Sens. Environ. 158, 15-27.

Bebi, P., Kulakowski, D., Veblen, T.T., 2003. Interactions between fire and spruce beetles in a subalpine Rocky Mountain forest landscape. Ecology 84, 362-371.

Bentz, B.J., Régnière, J., Fettig, C.J., Hansen, E.M., Hayes, J.L., Hicke, J.A., Kelsey, R.G., Negrón, J.F., Seybold, S.J., 2010. Climate Change and Bark Beetles of the Western

507 Bentz, B., Logan, J., MacMahon, J., Allen, C.D., Ayres, M., Berg, E., Carroll, A., Hansen, M., Hicke, J., Joyce, L., others, 2009. Bark beetle outbreaks in western North America:

509 Causes and consequences. Bark Beetle Symposium, Snowbird Utah. 
510 Berg, E.E., Henry, J.D., Fastie, C.L., De Volder, A.D., Matsuoka, S.M., 2006. Spruce beetle

511 outbreaks on the Kenai Peninsula, Alaska, and Kluane National Park and Reseve, Yukon

512 Territory: Relationship to summer temperatures and regional differences in disturbance

513 regimes. For. Ecol. Manag. 227, 219-232.

514 Bhandari, S., Phinn, S., Gill, T., 2012. Preparing Landsat image time series (LITS) for

515 monitoring changes in vegetation phenology in Queensland, Australia. Remote Sens. 4,

$516 \quad 1856-1886$.

517 Breiman, L., 2001. Random Forests. Mach. Learn. 45, 5-32.

518 Brown, M.G., Black, T.A., Nesic, Z., Fredeen, A.L., Foord, V.N., Spittlehouse, D.L., Bowler, R., 519 Burton, P.J., Trofymow, J.A., Grant, N.J., Lessard, D., 2012. The carbon balance of two 520 lodgepole pine stands recovering from mountain pine beetle attack in British Columbia. 521 Agric. For. Meteorol. 153, 82-93. doi:10.1016/j.agrformet.2011.07.010

522 Calderón, R., Navas-Cortés, J.A., Lucena, C., Zarco-Tejada, P.J., 2013. High-resolution airborne 523 hyperspectral and thermal imagery for early detection of Verticillium wilt of olive using 524 fluorescence, temperature and narrow-band spectral indices. Remote Sens. Environ. 139, $525 \quad$ 231-245. doi:10.1016/j.rse.2013.07.031

526 Carlson, K.M., Asner, G.P., Hughes, R.F., Ostertag, R., Martin, R.E., 2007. Hyperspectral

527 Remote Sensing of Canopy Biodiversity in Hawaiian Lowland Rainforests. Ecosystems

$528 \quad$ 10, 536-549. doi:10.1007/s10021-007-9041-z

529 Carter, G.A., 1994. Ratios of leaf reflectances in narrow wavebands as indicators of plant stress.

$530 \quad$ Int. J. Remote Sens. 15, 697-703.

531 Carter, G.A., 1993. Responses of Leaf Spectral Reflectance to Plant Stress. Am. J. Bot. 80, 239.

532 doi:10.2307/2445346 
533 Carter, G.A., Knapp, A.K., 2001. Leaf optical properties in higher plants: linking spectral

534 characteristics to stress and cholorophyll concentration. Am. J. Bot. 88, 677-684.

535 Cheng, T., Rivard, B., Sanchez-Azofeifa, G.A., Feng, J., Calvo-Polanco, M., 2010. Continuous

536 wavelet analysis for the detection of green attack damage due to mountain pine beetle

537 infestation. Remote Sens. Environ. 114, 899-910.

538 Coops, N.C., Johnson, M., Wulder, M.A., White, J.C., 2006a. Assessment of QuickBird high

539 spatial resolution imagery to detect red attack damage due to mountain pine beetle

$540 \quad$ infestation. Remote Sens. Environ. 103, 67-80.

541 Coops, N.C., Wulder, M.A., White, J.C., 2006b. Identifying and describing forest disturbance

542 and spatial pattern: data selection issues and methodological implications, in: Wulder,

543 M.A., Franklin, S.E. (Eds.), Understanding Forest Disturbance and Spatial Pattern:

$544 \quad$ Remote Sensing and GIS Approaches. Taylor \& Francis, pp. 31-61.

545 Crist, E.P., 1985. A TM tasseled cap equivalent transformation for reflectance factor data.

$546 \quad$ Remote Sens. Environ. 17, 301-306.

547 Curran, P.J., Dungan, J.., Peterson, D.L., 2001. Estimating the foliar biochemical concentration

548 of leaves with reflectance spectrometry: testing the Kokaly and Clark methodologies.

$549 \quad$ Remote Sens. Environ. 76, 349-359.

550 Dale, V.H., Joyce, L.A., Mcnulty, S., Neilson, R.P., Ayres, M.P., Flannigan, M.D., Hanson, P.J.,

551 Irland, L.C., Lugo, A.E., Peterson, C.J., Simberloff, D., Swanson, F.J., Stocks, B.J.,

552 Michael Wotton, B., 2001. Climate Change and Forest Disturbances. BioScience 51, 723.

$553 \quad$ doi:10.1641/0006-3568(2001)051[0723:CCAFD]2.0.CO;2 
554 Daughtry, C.S.T., Walthall, C.L., Kim, M.S., Brown de Colstoun, E., McMurtrey III, J.E., 2000.

555 Estimating corn leaf chlorophyll concentration from leaf and canopy reflectance. Remote

$556 \quad$ Sens. Environ. 74, 229-239.

557 Delalieux, S., Somers, B., Verstraeten, W.W., van Aardt, J.A.N., Keulmans, W., Coppin, P., 558 2009. Hyperspectral indices to diagnose leaf biotic stress of apple plants, considering leaf

559 phenology. Int. J. Remote Sens. 30. doi:10.1080/01431160802541556

560 Delalieux, S., Van Aardt, J., Keulemans, W., Schrevens, E., Coppin, P., 2007. Detection of biotic

561 stress (Venturia inaequalis) in apple trees using hyperspectral data: Non-parametric

562 statistical approaches and physiological implications. Eur. J. Agron. 27, 130-143.

563 Derderian, D.., Dang, H., Aplet, G.H., Binkley, D., 2016. Bark beetle effects on a seven-century

564 chronosequence of Engelmann spruce and subalpine fir in Colorado, USA. For. Ecol.

$565 \quad$ Manag. 361, 154-162.

566 DeRose, R.J., Long, J.N., 2012. Factors Influencing the Spatial and Temporal Dynamics of

567 Engelmann Spruce Mortality during a Spruce Beetle Outbreak on the Markagunt Plateau,

$568 \quad$ Utah. For. Sci. 58, 1-14. doi:10.5849/forsci.10-079

569 DeRose, R.J., Long, J.N., Ramsey, R.D., 2011. Combining dendrochronological data and the 570 disturbance index to assess Engelmann spruce mortality caused by a spruce beetle 571 outbreak in southern Utah, USA. Remote Sens. Environ. 115, 2342-2349.

$572 \quad$ doi:10.1016/j.rse.2011.04.034

573 Edburg, S.L., Hicke, J.A., Brooks, P.D., Pendall, E.G., Ewers, B.E., Norton, U., Gochis, D., 574 Gutmann, E.D., Meddens, A.J., 2012. Cascading impacts of bark beetle-caused tree 575 mortality on coupled biogeophysical and biogeochemical processes. Front. Ecol. Environ. $576 \quad 10,416-424$. doi:10.1890/110173 
577 Eng, J., 2005. Receiver operating characteristic analysis: a primer. Acad. Radiol. 12, 909-916.

578 Fassnacht, F.E., Latifi, H., Ghosh, A., Joshi, P.K., Koch, B., 2014. Assessing the potential of 579 hyperspectral imagery to map bark beetle-induced tree mortality. Remote Sens. Environ.

$580 \quad$ 140, 533-548. doi:10.1016/j.rse.2013.09.014

581 Fawcett, T., 2006. An introduction to ROC analysis. Pattern Recognit. Lett. 27, 861-874.

582 Frank, J.M., Massman, W.J., Ewers, B.E., Huckaby, L.S., Negrón, J.F., 2014. Ecosystem CO 2 $583 \quad / \mathrm{H}_{2} \mathrm{O}$ fluxes are explained by hydraulically limited gas exchange during tree mortality 584 from spruce bark beetles: $\mathrm{CO}_{2} / \mathrm{H}_{2} \mathrm{O}$ FLUX EXPLAINED FROM DISTURBANCE. J. $585 \quad$ Geophys. Res. Biogeosciences 119, 1195-1215. doi:10.1002/2013JG002597

586 Franklin, S.E., Wulder, M.A., Skakun, R.S., Carroll, A.L., 2003. Mountain pine beetle red-attack 587 forest damage classification using stratified Landsat TM data in British Columbia, 588 Canada. Photogramm. Eng. Remote Sens. 69, 283-288.

589 Gao, B., 1996. NDWI-A normalized difference water index for remote sensing of vegetation $590 \quad$ liquid water from space. Remote Sens. Environ. 58, 257-266.

591 Goodwin, N.R., Coops, N.C., Wulder, M.A., Gillanders, S., Schroeder, T., Nelson, T., 2008.

592 Estimation of insect infestation dynamics using a temporal sequence of Landsat data. $593 \quad$ Remote Sens. Environ. 112, 3680-3689.

594 Hall, R.J., Castilla, G., White, J.C., Cooke, B.J., Skakun, R.S., 2016. Remote sensing of forest 595 pest damage: a review and lessons learned from a Canadian perspective. Can. Entomol. $596 \quad$ doi:doi:10.4039/tce.2016.11

597 Hansen, E.M., Negron, J.F., Munson, A.S., Anhold, J.A., 2010. A retrospective assessment of 598 partial cutting to reduce spruce beetle-caused mortality in the southern Rocky Mountains.

599 West. J. Appl. For. 25, 81-87. 
600 Hart, S.J., Veblen, T.T., 2015. Detection of spruce beetle-induced tree mortality using high- and 601 medium-resolution remotely sensed imagery. Remote Sens. Environ. 168, 134-145. 602 doi:10.1016/j.rse.2015.06.015

603 Hart, S.J., Veblen, T.T., Eisenhart, K.S., Jarvis, D., Kulakowski, D., 2014. Drought induces 604 spruce beetle (Dendroctonus rufipennis) outbreaks across northwestern Colorado. $605 \quad$ Ecology 95, 930-939.

606 Hawkins, C.D.B., Dhar, A., Balliet, N.A., Runzer, K.D., 2012. Residual mature trees and 607 secondary stand structure after mountain pine beetle attack in central British Columbia.

608 For. Ecol. Manag. 277, 107-115. doi:10.1016/j.foreco.2012.04.023

609 Hebertson, E.G., Jenkins, M.J., 2008. Climate factors associated with historic spruce beetle 610 (Coleoptera: Curculionidae) outbreaks in Utah and Colorado. Environ. Entomol. 37, 281611292.

612 Hicke, J.A., Logan, J., 2009. Mapping whitebark pine mortality caused by a mountain pine beetle 613 outbreak with high spatial resolution satellite imagery. Int. J. Remote Sens. 30, 4427$614 \quad 4441$.

615 Humphreys, N., Safranyik, L., 1993. Spruce beetle (No. Foret Pest Leaflet 13). Natural 616 Resources Canada, Pacific Forestry Centre, Victoria, B.C.

617 Jenkins, M.J., Hebertson, E.G., Munson, A.S., 2014. Spruce beetle biology, ecology, and 618 management in the Rocky Mountains: an addendum to Spruce Beetles in the Rockies. $619 \quad$ Forests 5, 21-71.

620 Kautz, M., Dworschak, K., Gruppe, A., Schopf, R., 2011. Quantifying spatio-temporal dispersion 621 of bark beetle infestations in epidemic and non-epidemic conditions. For. Ecol. Manag. $622 \quad 262,598-608$. 
623 Kokaly, R.F., Asner, G.P., Ollinger, S.V., Martin, M.E., Wessman, C.A., 2009. Characterizing

624

625

626

627

628

629

630

631

632

633

634

635

636

637

638

639

640 Masaitis, G., Mozgeris, G., Augustaitis, A., 2013. Spectral reflectance properties of healthy and

641

642

643

644

645

canopy biochemistry from imaging spectroscopy and its application to ecosystem studies. Remote Sens. Environ. 113, S78-S91.

Kokaly, R.F., Clark, R.N., 1999. Spectroscopic determination of leaf biochemistry using banddepth analysis of absorption features and stepwise multiple linear regression. Remote Sens. Environ. 67, 267-287.

Kurz, W.A., Dymond, C.C., Stinson, G., Rampley, G.J., Neilson, E.T., Carroll, A.L., Ebata, T., Safranyik, L., 2008. Mountain pine beetle and forest carbon feedback to climate change. Nature 452, 987-990. doi:10.1038/nature06777

Liaw, A., Wiener, M., 2002. Classification and regression by randomForest. R News 2, 18-22.

Lillesand, T.M., Kiefer, R.W., Chipman, J., 2000. Remote Sensing and Image Analysis. Wiley, New York, NY.

Makoto, K., Tani, H., Kamata, N., 2013. High-resolution multispectral satellite image and a postfire ground survey reveal prefire beetle damage on snags in Southern Alaska. Scand. J. For. Res. 28, 581-585.

Malmstrom, C.M., Raffa, K.F., 2000. Biotic disturbance agents in the boreal forest: considerations for vegetation change models. Glob. Change Biol. 6, 35-48. stressed coniferous trees. IForest - Biogeosciences For. 6, 30-36. doi:10.3832/ifor0709006

McKenzie, D., Peterson, D.L., Littell, J.J., 2009. Chapter 15 Global Warming and Stress Complexes in Forests of Western North America, in: Developments in Environmental Science. Elsevier, pp. 319-337. 
646 Meddens, A.J.H., Hicke, J.A., 2014. Spatial and temporal patterns of Landsat-based detection of 647 tree mortality caused by mountain pine beetle outbreak in Colorado, USA. For. Ecol. $648 \quad$ Manag. 322, 78-88.

649 Meddens, A.J.H., Hicke, J., Ferguson, C.A., 2011. Evaluating the potential of multispectral 650 imagery to map multiple stages of tree mortality. Remote Sens. Environ. 115, 1632$651 \quad 1642$.

652 Meddens, A.J., Hicke, J.A., Ferguson, C.A., 2012. Spatiotemporal patterns of observed bark 653 beetle-caused tree mortality in British Columbia and the western United States. Ecol. $654 \quad$ Appl. 22, 1876-1891.

655 Merton, R., Huntington, J., n.d. Early simulation results of the ARIES-1 satellite sensor for 656 multi-temporal vegetation research derived from AVIRIS, in: Proceedings of the Eigth 657 Annual JPL Airborne Earth Science Workshop. Pasadena, CA: NASA, JPL, p. 1999. 658 Naidu, R.A., Perry, E.M., Pierce, F.J., Mekuria, T., 2009. The potential of spectral reflectance 659 technique for the detection of Grapevine leafroll-associated virus-3 in two red-berried 660 wine grape cultivars. Comput. Electron. Agric. 66, 38-45.

$661 \quad$ doi:10.1016/j.compag.2008.11.007

662 NCDC, 2016. Monthly Climatological Summary, Saint Elmo, CO US GHCND: USS0006L05S.

663 Niemann, K.O., Quinn, G., Visintini, F., Parton, D., 2015. Hyperspectral remote sensing of 664 mountain pine beetle with an emphasis on previsual assessment. Can. J. Remote Sens. 41, $665 \quad 191-202$.

666 Paine, T.D., Raffa, K.F., Harrington, T.C., 1997. Interactions among Scolytid bark beetles, their 667 assocaited fungi, and live host conifers. Annu. Rev. Entymology 42, 179-206. 
668 Penuelas, J., Pinol, J., Ogaya, R., Fillella, I., 1997. Estimation of plant water concentration by the 669 reflectance Water Index WI (R900/R970). Int. J. Remote Sens. 18.

670 doi:10.1080/014311697217396

671 Riano, D., Chuvieco, E., Salas, J., Aguado, I., 2003. Assessment of different topographic

672 corrections in Landsat-TM data for mapping vegetation types. IEEE Transations Geosci.

$673 \quad$ Remote Sens. 41, 1056-1061.

674 Roberts, D.A., Roth, K.L., Perroy, R.L., 2012. Hyperspectral vegetation indices, in: Thenkabail,

675 P.S., Lyon, J.G., Huete, A. (Eds.), Hyperspectral Remote Sensing of Vegetation. CRC

676 Press: Taylor \& Francis Group, Boca Raton, FL, pp. 309-328.

677 Santos, M.J., Greenberg, J.A., Ustin, S.L., 2010. Using hyperspectral remote sensing to detect 678 and quantify southeastern pine senescence effects in red-cockaded woodpecker (Picoides 679 borealis) habitat. Remote Sens. Environ. 114, 1242-1250.

680 Schmid, J.M., 1976. Temperatures, growth, and fall of needles on Engelmann spruce infested by 681 spruce beetles. (Forest Service Research Note No. RM-331). USDA.

682 Schmid, J.M., Frye, R.H., 1977. Spruce beetle in the Rockies.

683 Schmid, J.M., Frye, R.H., 1972. Biological evaluation of spruce beetle mortality, Wolf Creek 684 Pass, CO (USDA Forest Service, Rocky Mountain Forest and Range Experiment Station $685 \quad$ No. Unumbered Report). Fort Collins, CO.

686 Sherriff, R.L., Berg, E.E., Miller, A.E., 2011. Climate variability and spruce beetle 687 (Dendroctonus rufipennis) outbreaks in south-central and southwest Alaska. Ecology 92, $688 \quad 1459-1470$. 
689 Skakun, R.S., Wulder, M.A., Franklin, S.E., 2003. Sensitivity of the thematic mapper enhanced 690 wetness difference index to detect mountain pine beetle red-attack damage. Remote Sens. 691 Environ. 86, 433-443. doi:10.1016/S0034-4257(03)00112-3

692 Smith, K.L., Steven, M.D., Colls, J.J., 2004. Use of hyperspectral derivative ratios in the red693 edge region to identify plant stress response to gas leaks. Remote Sens. Environ. 92, 207694217.

695 Strobl, C., Boulesteix, A.L., Hothorn, T., 2007. Bias in random forest variable importance 696 measures: Illustrations, sources and a solution. BMC Bioinformatics 8. doi:10.1186/1471-2105-8-25

698 Thenkabail, P.S., Lyon, J.G., Huete, A., 2012a. Advances in hyperspectral remote sensing of 699 vegetation and agricultural croplands, in: Hyperspectral Remote Sensing of Vegetation. $700 \quad$ CRC Press: Taylor \& Francis Group, pp. 3-35.

701 Thenkabail, P.S., Lyon, J.G., Huete, A., 2012b. Hyperspectral remote sensing of vegetation and 702 agricultural crops: knowledge gain and knowledge gap after 40 years of research, in: Thenkabail, P.S., Lyon, J.G., Huete, A. (Eds.), Hyperspectral Remote Sensing of Vegetation. CRC Press: Taylor \& Francis Group, Boca Raton, FL, pp. 663-688.

705 Tucker, C.J., 1979. Red and photographic infrared linear combinations for monitoring 706 vegetation. Remote Sens. Environ. 8, 127-150.

707 Underwood, E., Ustin, S., DiPietro, D.B., 2003. Mapping nonnative plants using hyperspectral 708 imagery. Remote Sens. Environ. 86, 150-161.

709 USFS, 2016. Aerial Survey Highlights for Colorado 2015 [WWW Document]. URL

710 http://www.fs.usda.gov/detail/r2/forest-grasslandhealth/?cid=fseprd489834 
711 USGS, 2016. Frequently Asked Questions about the Landsat Missions [WWW Document].

$712 \quad$ USGS Landsat Missions. URL

713 http://landsat.usgs.gov/band_designations_landsat_satellites.php

714 Ustin, S.L., Roberts, D.A., Gamon, J.A., Asner, G.P., Green, R.O., 2004. Using imaging

715 spectroscopy to study ecocystem processes and properties. BioScience 54, 523-534.

716 Veblen, T.T., Hadley, K.S., Reid, M.S., Rebertus, A.J., 1991. The Response of Subalpine Forests

717 to Spruce Beetle Outbreak in Colorado. Ecology 72, 213. doi:10.2307/1938916

718 Walter, J.A., Platt, R.V., 2013. Multi-temporal analysis reveals that predictors of mountain pine

719 beetle infestation change during outbreak cycles. For. Ecol. Manag. 302, 308-318.

$720 \quad$ doi: $10.1016 /$ j.foreco.2013.03.038

721 Westerling, R.J., Hidalgo, H.G., Cayan, D.R., Swetnam, T.W., 2006. Warmer and earlier spring

722 increases western US forest wildfire activity. Science 313, 940-943.

723 White, J.C., Coops, N.C., Hilker, T., Wulder, M.A., Carroll, A.L., 2007. Detecting mountain

724 pine beetle red attack damage with EO-1 Hyperion moisture indices. Int. J. Remote Sens.

$725 \quad 28,2111-2121$.

726 White, J.C., Wulder, M.A., Brooks, D., Reich, R., Wheate, R.D., 2005. Detection of red attack

727 stage mountain pine beetle infestation with high spatial resolution satellite imagery.

$728 \quad$ Remote Sens. Environ. 96, 340-351.

729 Wulder, M.A., Dymond, C.C., White, J.C., Leckie, D.G., Carroll, A.L., 2006a. Surveying

730 mountain pine beetle damage of forests: A reivew of remote sensing opportunities. For.

$731 \quad$ Ecol. Manag. 221, 27-41. 
732 Wulder, M.A., White, J.C., Bentz, B., Alvarez, M.F., Coops, N.C., 2006b. Estimating the

733 probability of mountain pine beetle red-attack damage. Remote Sens. Environ. 101, 150-

$734 \quad$ 166. doi:10.1016/j.rse.2005.12.010

735 Wulder, M.A., White, J.C., Bentz, B.J., Ebata, T., 2006c. Augmenting the existing survey

736 hierarchy for mountain pine beetle red-attack damage with satellite remotely sensed data.

$737 \quad$ For. Chron. 82, 187-202.

738

739 


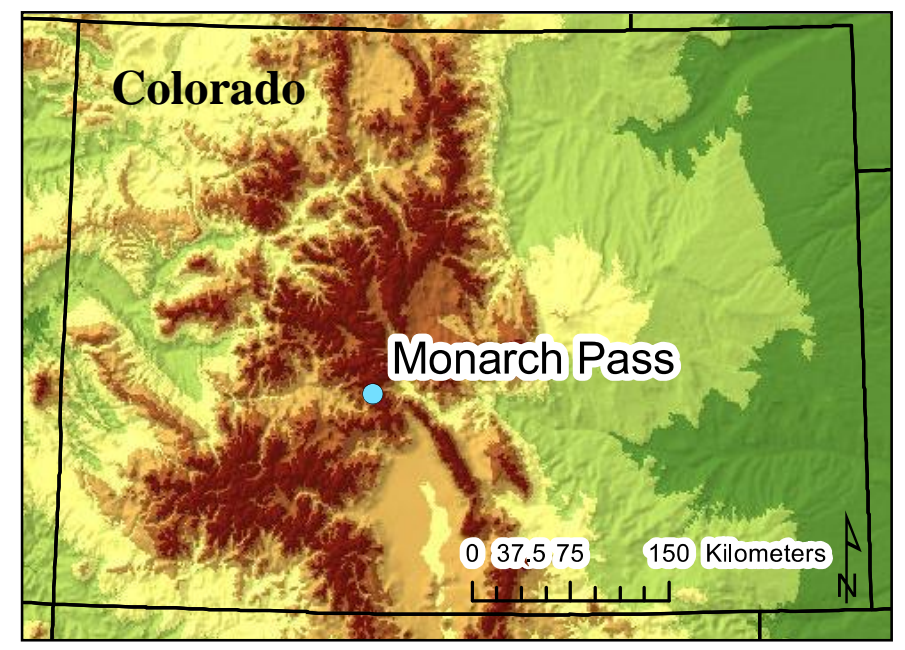

Figure 1. Location of the study site Monarch Pass in central Colorado. 


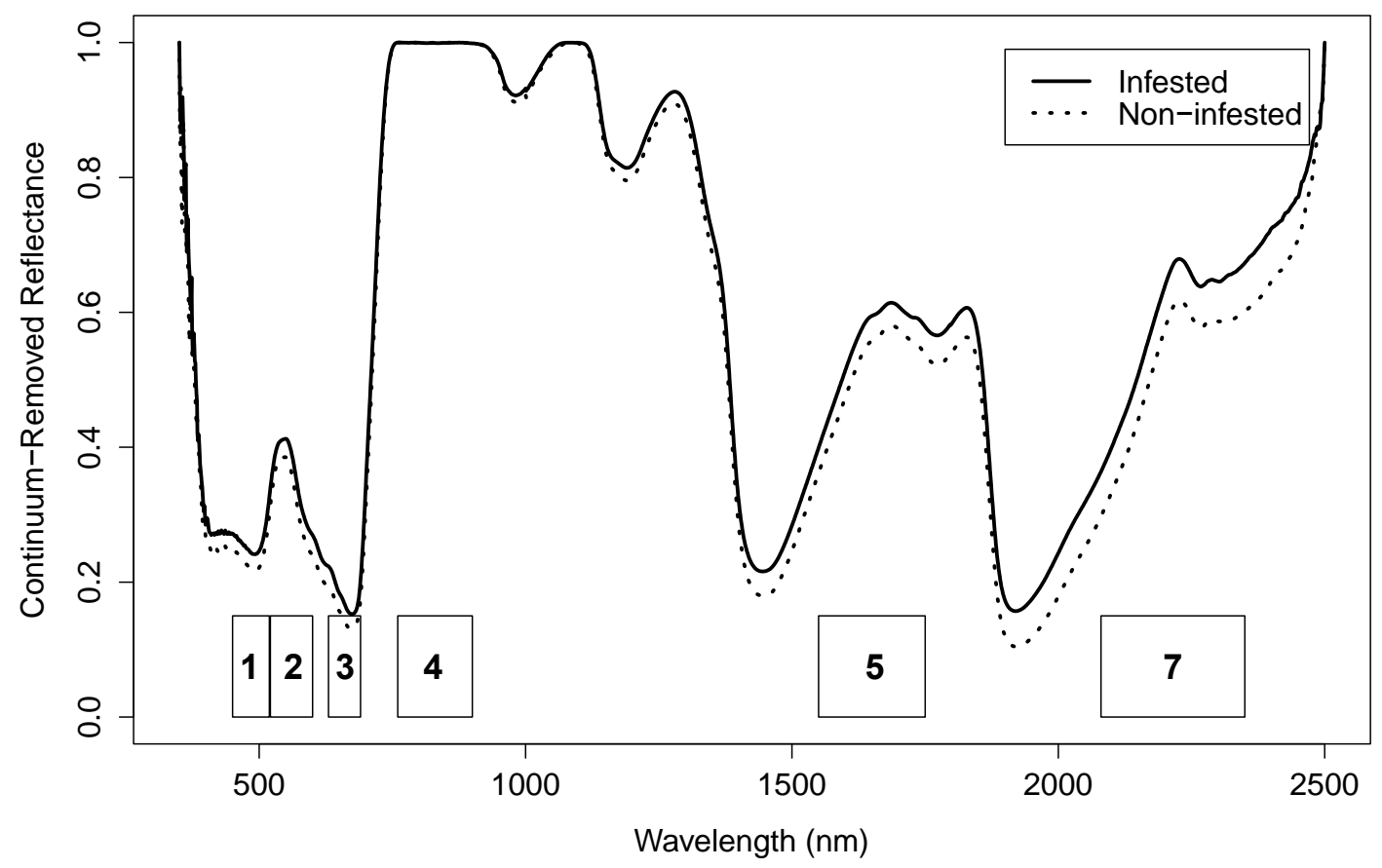

Figure 2. Average continuum-removed spectral reflectance for infested (solid) and noninfested (dashed) Engelmann spruce trees along with $95 \%$ confidence intervals for both spectra $\left(\mathrm{CI}=\bar{x} \pm 2.14 S E_{\bar{x}}\right)$. Colored bars represent the wavelength location of Landsat bands. 


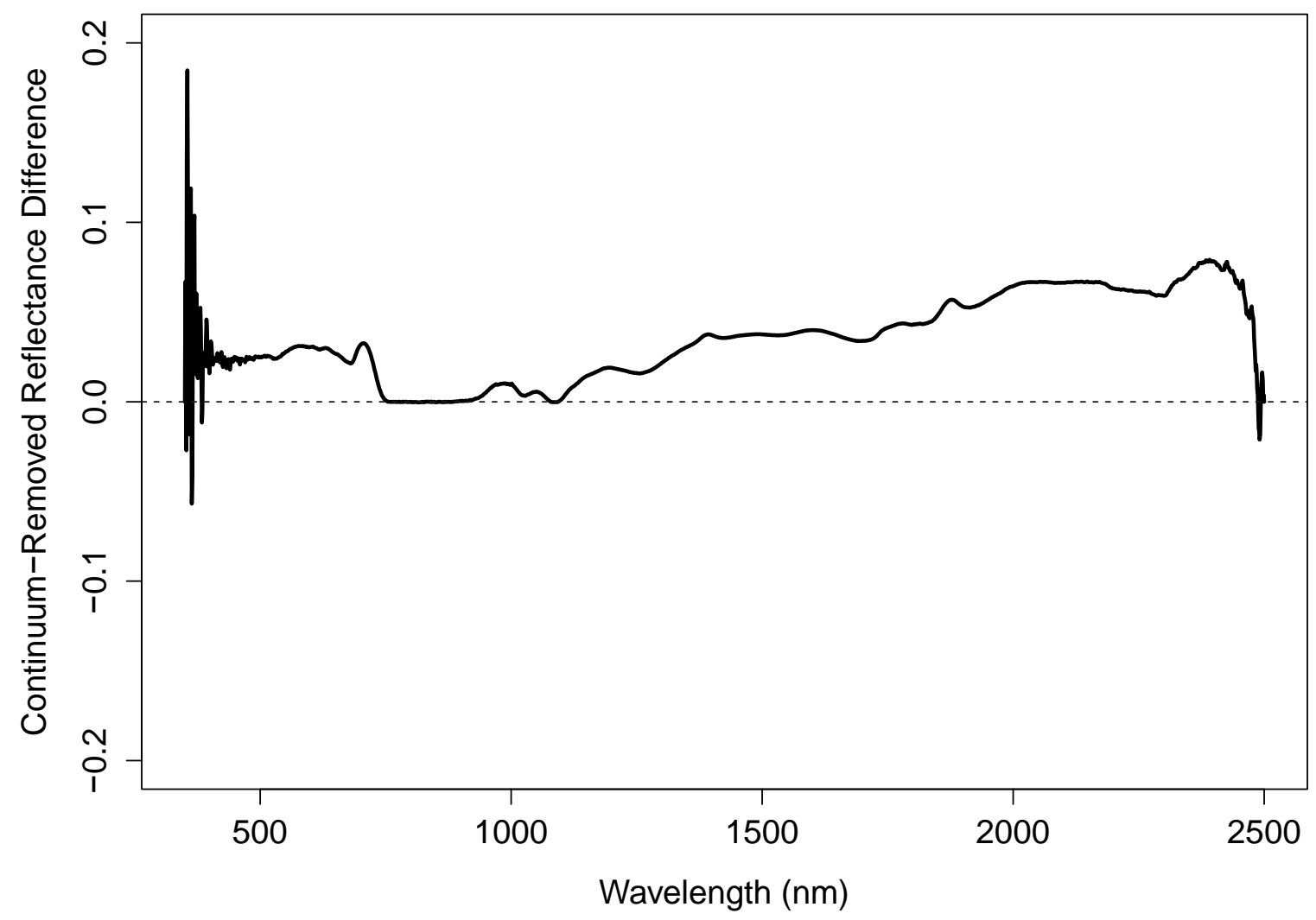

Figure 3. Average continuum-removed spectral difference between infested and non-infested Engelmann spruce trees (difference $=$ infested - non-infested). Shaded bar represents $95 \%$ confidence intervals $\left(\mathrm{CI}=\bar{x} \pm 2.14 S E_{\bar{x}}\right)$. 


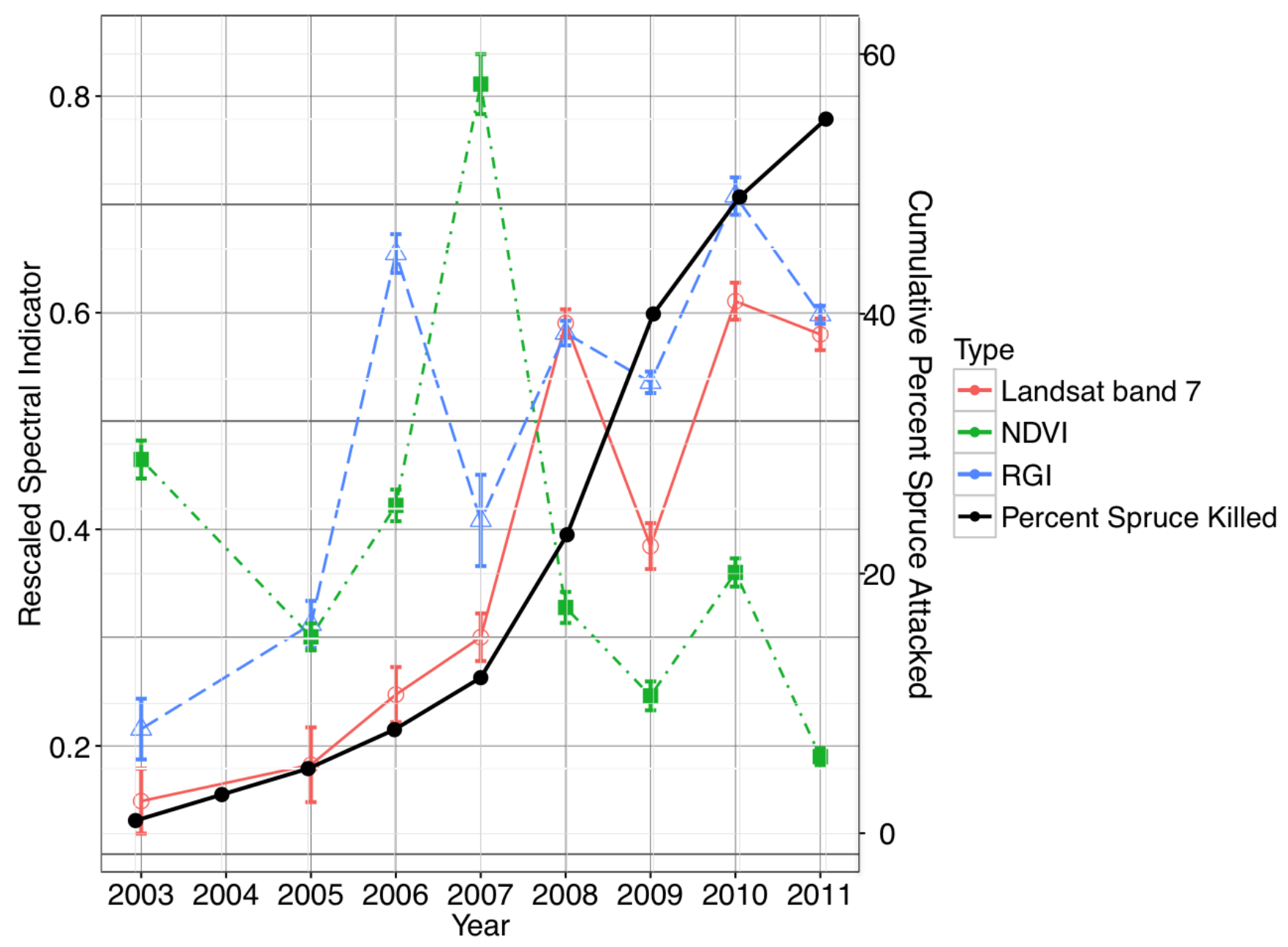

Figure 4. Average rescaled relative normalized digital number values for Landsat band 7, RGI, and NDVI for forested plots at GLEES during a spruce beetle infestation along with cumulative percent spruce trees attacked redrawn from Frank et al. (2014). Error bars on the spectral indicators represent confidence intervals $\left(C I=\bar{x} \pm 1.99 S E_{\bar{x}}\right)$. 


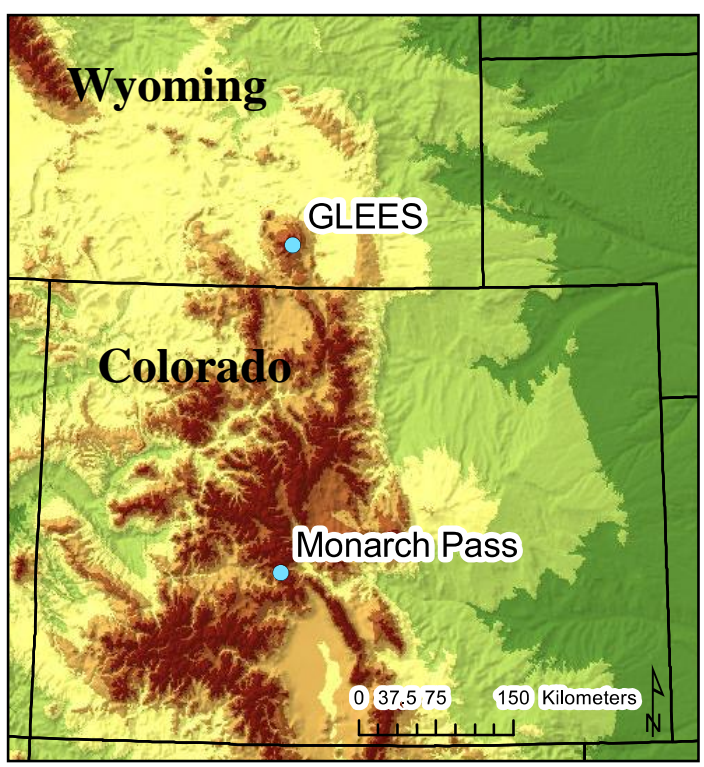

Figure A.1. Location of the study sites GLEES (southern Wyoming) and Monarch Pass (central Colorado). 
Table 1. Vegetation indices and Landsat bands used to detect spruce beetle infestation in Engelmann spruce. Blue, green, red, NIR, SWIR1, and SWIR2 were calculated using wavelengths corresponding to Landsat TM bands.

\begin{tabular}{|c|c|c|}
\hline $\begin{array}{l}\text { Vegetation Index or } \\
\text { Band Name }\end{array}$ & Equation or Wavelength Range & Reference \\
\hline RGI & Red/Green & Coops et al., 2006a \\
\hline MCARI & $\begin{array}{l}{\left[\left(\mathrm{R}_{700 \mathrm{~nm}}-\mathrm{R}_{670 \mathrm{~nm}}\right)-0.2\left(\mathrm{R}_{700 \mathrm{~nm}}-\right.\right.} \\
\left.\left.\mathrm{R}_{550 \mathrm{~nm}}\right)\right]^{*}\left(\mathrm{R}_{700 \mathrm{~nm}} / \mathrm{R}_{670 \mathrm{~nm}}\right)\end{array}$ & Daughtry et al., 2000 \\
\hline WI & $\mathrm{R}_{900 \mathrm{~nm}} / \mathrm{R}_{970 \mathrm{~nm}}$ & Penuelas et al., 1997 \\
\hline TCWET & $\begin{array}{l}\text { Blue*0.0315 + Green*2.201+ } \\
\text { Red*0.3102 + NIR*0.1594+ } \\
\text { SWIR1*0.6806 - SWIR2*0.6109 }\end{array}$ & Crist 1985 \\
\hline TCGRE & $\begin{array}{l}\text { Blue*-0.1603 - Green*0.281 - }^{*} \text { Red*0.4934 - NIR*0.7940 + } \\
\text { SWIR1*0.0002-SWIR2*0.1444 }\end{array}$ & Crist 1985 \\
\hline TCBRI & $\begin{array}{l}\text { Blue*0.2043 + Green*0.458 + } \\
\text { Red*0.5524 + NIR*0.5741 + } \\
\text { SWIR1*0.3124 + SWIR2*0.2303 }\end{array}$ & Crist 1985 \\
\hline DI & TCBRI - TCWET - TCGRE & DeRose et al., 2011 \\
\hline NDVI & $(\mathrm{NIR}-\mathrm{Red}) /(\mathrm{NIR}+\mathrm{Red})$ & Tucker 1979 \\
\hline NDMI & $(\mathrm{NIR}-\mathrm{SWIR} 1) /(\mathrm{NIR}+\mathrm{SWIR} 1)$ & Gao 1996 \\
\hline RVSI & $\left(\mathrm{R}_{714 \mathrm{~nm}}+\mathrm{R}_{752 \mathrm{~nm}}\right) / 2-\mathrm{R}_{733 \mathrm{~nm}}$ & $\begin{array}{l}\text { Merton \& } \\
\text { Huntington } 1999\end{array}$ \\
\hline Landsat band 5 & 1550 to $1750 \mathrm{~nm}$ & USGS 2014 \\
\hline Landsat band 7 & 2080 to $2350 \mathrm{~nm}$ & USGS 2014 \\
\hline
\end{tabular}


Table 2. Area under the curve (AUC), accuracy, false positive rate, and false negatiz 52 ate for the eight wavelengths with highest variable importance from the random forest tes 3 and for the vegetation indices and Landsat bands from Table 1 (ordered by accuracy $54 d$ wavelength). Contingency tables used to calculate error rates can be found in Table $\$ 5515 i n$ the Supplementary Material.

756

\begin{tabular}{|l|l|l|l|l|}
\hline $\begin{array}{l}\text { Wavelengths } \\
\text { chosen from } \\
\text { random forest } \\
\text { test (nm) }\end{array}$ & AUC & Accuracy & False Positives & False Negatives \\
\hline 1062 & 0.93 & 0.93 & 0.13 & \\
\hline 1061 & 0.93 & 0.93 & 0.067 & 0 \\
\hline 1059 & 0.93 & 0.93 & 0.067 & 0.067 \\
\hline 862 & 0.93 & 0.93 & 0.067 & 0.067 \\
\hline 861 & 0.93 & 0.93 & 0.067 & 0.067 \\
\hline 764 & 0.93 & 0.93 & 0.13 & 0.067 \\
\hline 368 & 0.93 & 0.93 & 0 & 0 \\
\hline 1056 & 0.9 & 0.9 & 0 & 0.13 \\
\hline $\begin{array}{l}\text { VIs and } \\
\text { Landsat bands }\end{array}$ & & & & 0.2 \\
\hline Landsat band 7 & 0.83 & 0.8 & 0.26 & \\
\hline NDVI & 0.8 & 0.83 & 0.5 & 0.067 \\
\hline RGI & 0.8 & 0.8 & 0.3 & 0.4 \\
\hline WI & 0.8 & 0.8 & 0.067 & 0.067 \\
\hline Landsat band 5 & 0.77 & 0.8 & 0.13 & 0.33 \\
\hline DI & 0.77 & 0.77 & 0.2 & 0.53 \\
\hline NDMI & 0.77 & 0.77 & 0.13 & 0.267 \\
\hline TCBRI & 0.77 & 0.77 & 0.067 & 0.33 \\
\hline TCGRE & 0.77 & 0.77 & 0 & 0.4 \\
\hline RVSI & 0.67 & 0.77 & 0.13 & 0.467 \\
\hline MCARI & 0.63 & 0.67 & 0.2 & 0.53 \\
\hline TCWET & 0.63 & 0.63 & 0.2 & 0.53 \\
\hline
\end{tabular}


Table 3. $T$-test $(n=30)$ results for the eight wavelengths with highest variable importanf 64 from the random forest test, and the chosen vegetation indices and Landsat band 7. 765 Wavelengths and aggregated indices/wavebands ordered by difference between infested and non-infested spectra.

\begin{tabular}{|l|l|l|l|}
\hline $\begin{array}{l}\text { Wavelengths chosen } \\
\text { from random forest } \\
(\mathbf{n m})\end{array}$ & $\begin{array}{l}\text { Difference between } \\
\text { Infested and Non- } \\
\text { Infested (nm) }\end{array}$ & t-statistic & p-value \\
\hline 368 & 0.09513 & -4.86 & $7.11 \mathrm{E}-05$ \\
\hline 1056 & 0.0051 & -5.43 & $5.56 \mathrm{E}-05$ \\
\hline 1059 & 0.00466 & -5.28 & $8.12 \mathrm{E}-05$ \\
\hline 1061 & 0.00433 & -5.1614 & $1.03 \mathrm{E}-04$ \\
\hline 1062 & 0.00411 & -5.053 & 0.00013 \\
\hline 861 & 0.00023 & 5.91 & $4.09 \mathrm{E}-06$ \\
\hline 862 & 0.00021 & 5.98 & $1.95 \mathrm{E}-06$ \\
\hline 764 & $9 \mathrm{E}-05$ & 4.7132 & $1.80 \mathrm{E}-04$ \\
\hline $\begin{array}{l}\text { VIs and Landsat } \\
\text { bands }\end{array}$ & & & \\
\hline Landsat band 7 & 0.06435 & & \\
\hline RGI & 0.03237 & -3.6487 & $1.60 \mathrm{E}-03$ \\
\hline NDVI & 0.03685 & -3.031 & $5.59 \mathrm{E}-03$ \\
\hline WI & 0.011 & 2.8429 & $8.77 \mathrm{E}-03$ \\
\hline
\end{tabular}

